\title{
KEPEMIMPINAN DAN KOMUNIKASI BAGI COMMUNITY DEVELOPMENT COMMITTEE DI WILAYAH CAKUNG - JAKARTA
}

\author{
Christine Winstinindah Sandroto ${ }^{1}$ \\ ${ }^{1}$ Fakultas Ekonomi dan Bisnis \\ Universitas Katolik Indonesia Atma Jaya \\ christine.wins@atmajaya.ac.id
}

\begin{abstract}
ABSTRAK
Yayasan Gugah Nurani Indonesia (GNI) masih dalam proses berkembang dan perlu membenahi kepemimpinan dan manajemennya. Dalam proses training needs analysis untuk mengetahui pelatihan apa yang dibutuhkan, ternyata dibutuhkan pelatihan kepemimpinan dan komunikasi bagi Community Development Project (CDP) Community Development Committee di wilayah Cakung - Jakarta Timur. Pelatihan ini dirasa penting agar bagi CDP Community Development Committee di wilayah Cakung dapat lebih efektif menjangkau masyarakat yang menjadi dampingan dan binaannya. Khalayak sasaran adalah masyarakat binaan GNI di Cakung, Kelompok Pemuda Itermasuk relawan GNI, dan Staf CDP). Selama berlangsungnya kegiatan, pelatihan dan pengembangan ini mendapatkan respon yang positif. Khalayak sasaran aktif terlibat dalam diskusi dan tanya jawab. Juga setelah kegiatan proses pendampingan dan edukasi terhadap komunitas di Cakung yang dilakukan oleh CDC \& Kelompok orangtua KENARI di Cakung, Kelompok Pemuda/termasuk relawan GNI, dan Staf CDP menjadi lebih efektif dan komunikasi berjalan lebih baik. Ke depannya pengembangan masyarakat Cakung akan terus dilakukan. Evaluasi kegiatan akan dilaksanakan tidak hanya laporan kegiatan, namun juga dilakukan laporan naratif, monitoring dan evaluasi terhadap pelatihan dan pengembangan, juga pendampingan (Pemantauan dan evaluasi lapangan akan dilaksanakan untuk mengumpulkan data, dokumen, informasi (kualitatif \& kuantitatif) terkait dengan pengelolaan resiko atas kegiatan), dan cross-learning.
\end{abstract}

Kata kunci: kepemimpinan; komunikasi; pelatihan dan pengembangan

\section{PENDAHULUAN}

Pelatihan dan pengembangan merupakan salah satu cara yang dibutuhkan untuk mengembangkan manusia Indonesia. Pendidikan tinggi yang berkelanjutan penting untuk diraih, namun itu membutuhkan waktu dan biaya yang tidak sedikit. Dalam jangka pendek untuk mengejar ketertinggalan pelatihan dan pengembangan manusia lebih mungkin untuk diraih. Dalam konteks organisasi, menurut Noe (2010), training refers to a planned effort by a company to facilitate employees' learning of job related competencies. Dalam hal ini pembelajaran harus bersifat berkelanjutan. Continues learning requires employees to understand the entire work system, including the relationship among their jobs, their work units, and the company. Snell dan Bohlander (2013) mengemukakan perbedaan pelatihan dan pengembangan sebagai berikut, training: effort initiated by an organization to foster learning among its members and tends to be narrowly focused and oriented toward short-term performance concerns, sedangkan development: effort that is oriented more toward broadening an individual's skills for the future responsibilities. Walaupun terdapat perbedaan, namun pada prakteknya saat ini tidak pernah lagi dibedakan apakah aktivitas yang berlangsung adalah pelatihan ataukah pengembangan, dan sering disebut sebagai kesatuan yaitu pelatihan dan pengembangan.

Salah satu skill yang perlu dilatih dan dikembangkan adalah kepemimpinan dan komunikasi. Menurut Daft (2015), leadership is Influence based relationship among leaders and followers who intend real changes and outcomes that reflect their shared purposes. Jadi kepemimpinan bicara mengenai pengaruh antara pemimpin dan pengikut. Seorang pemimpin mutlak harus memiliki kemampuan komunikasi yang baik. 
Penulis merasa terpanggil untuk mendarmabaktikan ilmu dengan mengembangkan masyarakat Indonesia. Disini penulis ikut mengembangkan dan mengedukasi lembaga swadaya masyarakat "Yayasan Gugah Nurani Indonesia (GNI)" yang bergerak di bidang kemanusiaan dan pembangunan dengan Status Badan Penasehat Umum oleh UN ECOSOC. GNI merupakan salah satu afiliasi dari Good Neighbors International, sebuah organisasi non pemerintah internasional. Hingga kini, Yayasan Gugah Nurani Indonesia sudah memiliki 17 wilayah dampingan yang dikenal dengan istilah CDP (community development project) yang tersebar di beberapa kelurahan/desa di Pulau Jawa Sumatera, Sulawesi, Nusa Tenggara Barat, Nusa Tenggara Timur dengan penerima manfaat lebih dari 13.000 anak. Dalam konteks proyek Training for Batavia CDP Community Development Committee, GNI memiliki 3 wilayah dampingan di Jakarta yaitu Cakung, Menteng Tenggulun, dan Rawa Badak Selatan. (Gugah Nurani Indonesia, 2017). Kali ini kami melakukan pengabdian masyarakat di wilayah Cakung.

GNI masih dalam proses berkembang dan perlu membenahi kepemimpinan dan manajemennya. Dalam proses traning needs analysis untuk mengetahui pelatihan apa yang dibutuhkan, ternyata dibutuhkan pelatihan kepemimpinan dan komunikasi bagi CDP Community Development Committee di wilayah Cakung - Jakarta Timur. Pelatihan ini dirasa penting agar bagi CDP Community Development Committee di wilayah Cakung dapat lebih efektif menjangkau masyarakat yang menjadi dampingan dan binaannya. Diharapkan dengan adanya pelatihan ini, GNI mendapatkan pengetahuan dan keterampilan kepemimpinan dan manajemen, serta kemampuan komunikasi untuk mengelola organisasi dengan baik agar dapat mencapai tujuan lebih efektif dan strategis.

\section{METODE KEGIATAN}

Kegiatan pengabdian masyarakat ini dilaksanakan selama empat bulan, yaitu mulai Desember 2017 hingga Maret 2018. Tahap awal dimulai dengan melakukan training needs analysis (TNA). Strategic training needs analysis identifies the training employees will need to fill these future jobs (Dessler, 2017). Setelah dilakukan TNA, maka ditemukan kebutuhannya, yaitu terhadap pelatihan Kepemimpinan dan Komunikasi, maka dilanjutkan dengan aktivitas pengembangan berikutnya guna implementasi dan realisasi. Kegiatan TNA dan rapat banyak dilakukan di kampus Unika Atma Jaya. Namun aktivitas pengembangan khalayak sasaran dilaksanakan di Kantor Kelurahan Cakung Timur.

Aktivitas pengembangan di Cakung dimulai dengan :1). Persiapan Proyek: Konfirmasi GNI dengan pihak sekolah dan guru-guru yang akan terlibat sebagai peserta proyek Training for Batavia CDP Community Development Committee; 2). Menyusun Jadwal pelaksanaan di tiaptiap sekolah dan komunitas dampingan GNI; 3). Assessment Pengelolaan CDC di masingmasing wilayah dampingan; dan 4). Training Pengelolaan dengan Modul Kepemimpinan dan Komunikasi

Metode yang dipilih adalah pelatihan dan pengembangan (ceramah, diskusi, tanya jawab, games, yang seluruh penyampaiannya disesuaikan dengan gaya bahasa dan tingkat pendidikan khalayak sasaran), serta pembimbingan dan pendampingan dengan berbagi ilmu dan pengalaman kepada khalayak sasaran dan mitra. Khalayak sasaran adalah masyarakat binaan GNI (CDC \& Kelompok orangtua KENARI di Cakung, Kelompok Pemuda /termasuk relawan GNI, dan Staf CDP). Sebagian besar dari CDC adalah ibu-ibu yang berprofesi sebagai guru PAUD dan sekolah dasar, juga para pedagang di pasar yang tergolong dalam pengusaha mikro. Jenis usaha atau dagangan mereka adalah pedagang nasi uduk, bubur, gorengan, pulsa, baju, dan sebagainya. 


\section{HASIL DAN PEMBAHASAN}

Profil CDP Community Development Committee di wilayah dampingan Cakung adalah sebagai berikut: Cakung CDP terletak di Jalan Tambun Rengas RT. 06, RW. 07 No. 09, Cakung Timur. Terdapat 500 anak dan 2.500 kepala keluarga yang yang didukung oleh GNI. Daerah ini dapat dikategorikan sebagai "masyarakat terpinggirkan". Adapun situasi dan kondisi komunitas adalah sebagai berikut: 1). Rata-rata pendapatan per bulan di daerah ini adalah Rp. 1.000.000, -; 2). Jumlah rata-rata kepemilikan ternak (unggas) adalah 9 ekor per rumah tangga; 3). Kepemilikan tanah rata-rata dari 0,0025 hektar; 4). Tingkat anak-anak yang tidak memiliki akses ke sekolah anak usia dini atau penitipan mencapai 46,9\%; 5). Angka partisipasi SD: lakilaki (53,59\%), perempuan (46,40\%); 6). Angka partisipasi SMP: laki-laki (53,27\%), perempuan $(46,72 \%)$; 7). Tingkat buta huruf $31,2 \%$; dan 8$)$. Tingkat partisipasi perempuan dalam kegiatan ekonomi $30 \%$.

GNI melaksanakan program Peningkatan Pendapatan keluarga. Dalam program ini ada beberapa kegiatan antara lain; Kelompok ekonomi produktif, Kredit usaha kecil dan bank sampah. Ditempat ini anak-anak juga diajarkan menabung dan juga kegiatan luar sekolah (Olahraga, Menulis, Kelas Musik, Bahasa Inggris dan Komputer). Pada pelaksanaannya GNI telah mendukung wilayah-wilayah yang termasuk kategori marjin dengan tingkat perekonomian keluarga yang rendah, minim akan akses pendidikan, sanitasi dan air, serta kesehatan. Berangkat dari keadaan ini tentu diperlukannya pemimpin masyarakat yang peduli untuk membangun komunitasnya dengan sumberdaya atau potensi lokal yang ada di dalam komunitas tersebut. Namun, tidak cukup pada tahap 'peduli' sangat dibutuhkan partisipasi dari masyarakat lokal untuk membangun komunitasnya menuju kemandirian dan keberlanjutan dalam aspek sosial, ekonomi, budaya, dan lingkungan. Untuk merespon hal ini maka GNI menginisiasi pembentukkan suatu komite pemberdayaan masyarakat yang selanjutnya komite ini akan disebut dengan nama Community Development Committee (CDC). CDC ini adalah mitra GNI yang merupakan perwakilan dari berbagai lapisan dalam masyarakat, memiliki kepekaan dan kepedulian serta komitmen untuk membangun masyarakat dalam komunitasnya dengan konsep pemberdayaan partisipatif. (Gugah Nurani Indonesia, 2017). Untuk itulah mengapa pelatihan dan pengembangan khalayak sasaran dengan topik kepemimpinan dan komunikasi dibutuhkan di CDP Cakung.

\section{Pelatihan dan Pengembangan dengan topik:Kepemimpinan dan Komunikasi}

Adapun tujuan dari pelatihan dan pengembangan ini adalah: 1). agar khalayak sasaran memahami hakekat pemimpin adalah memberikan pengaruh dan perubahan bagi lingkungan; 2). Khalayak sasaran memahami perbedaan antara pemimpin dan manajer; dan 3). Khalayak sasaran memahami pentingnya komunikasi yang efektif bagi seorang pemimpin.

\section{Point penting dalam Pelatihan dan Pengembangan: Kepemimpinan Dan Komunikasi A. Kepemimpinan}

Program pelatihan kepemimpinan didefinisikan sebagai: programs that have been systematically designed to enhance leader knowl-edge, skills, abilities, and other components (Day in Lacerenza., at al 2017), sedangkan kepemimpinan didefinisikan sebagai proses yang melibatkan pengaruh yang tidak memaksakan, dan ini merupakan seperangkat atribut untuk mempengaruhi dengan berhasil. Pengaruh dalam hal ini adalah kemampuan untuk mempengaruhi persepsi, keyakinan, sikap, motivasi, dan atau perilaku pihak lain (Moorhead and Griffin, 2012). 
Dari masa ke masa pemimpin yang dicari mengalami perubahan, tetapi pada intinya adalah terdapat lima elemen kunci dari kepemimpinan yaitu: 1. Pengaruh; 2. Tujuan organisasi; 3. Orang-orang; 4. Perubahan; 5. Pemimpin dan pengikut.(Achua and Lussier, 2013). Pemimpin yang efektif tahu kapan ia harus memimpin dan kapan harus mengikuti, mempengaruhi pengikut untuk mendukung minat-minat organisasi, memberikan arah, menetapkan tujuan yang menantang dan memimpinnya untuk dapat mencapai tujuan, mempengaruhi perubahan bagi peningkatan berkelanjutan, dan menikmati bekerja dengan orang-orang. Sedangkan traits dari pemimpin yang efektif adalah memiliki: integritas, fleksibilitas, sensitif terhadap orang lain, inteligence, stabilitas, percaya diri, dominan, berenergi tinggi, dan memiliki internal locus of control. Teori-teori kepemimpinan itu sendiri dapat diklasifikasikan atas trait theory of leadership, behavior theories of leadership, contingency leadership, dan integrative theory of leadership.

Pemimpin dan manajer pada dasarnya terdapat perbedaan. Kepemimpinan merupakan kemampuan untuk memotivasi orang lain untuk bertindak mencapai visi dan misi perusahaan. Pemimpin yang memiliki visi masa depan akan mengantisipasi ketidakpastian, sedangkan managerial adalah kemampuan memotivasi orang lain atas dasar kinerja organisasi. Orientasinya pada perencanaan, pengorganisasian, pelaksanaan, penilaian kinerja dan pengawasan.

Salah satu pandangan kontemporer tentang kepemimpinan saat ini adalah kepemimpinan team. Karakteristik dari kepemimpinan team adalah: kesediaan membagi informasi, dapat mempercayai orang lain dan menyerahkan sebagian otoritasnya, dan paham kapan ia harus mengintervensi. Tugas dari seorang pemimpin team adalah mengelola team's external boundary dan memfasilitasi proses team, seperti coaching, facilitating, handling disciplinary problems, menilai kinerja team dan individu, serta komunikasi.

\section{B. KOMUNIKASI}

As leadership is a highly social phenomenon, communication is an essential activity for a leader. Obviously, the content of aleader's communication is important for subordinates. However, the way a leader communicates may be equally important for subordinates (Pieper and de Vries, 2013). Komunikasi adalah proses penyampaian pesan yang mengandung makna tertentu dimana salah satu pihak ada yang berfungsi sebagai pengirim dan di satu pihak ada yang berfungsi sebagai penerima, dengan tujuan untuk saling mengerti (Lihat Gambar1). Beberapa saluran komunikasi diantaranya adalah face-to-face, telephone, group meetings, presentasi, memo, surat, teleconference, videoconference, dan lain sebagainya.

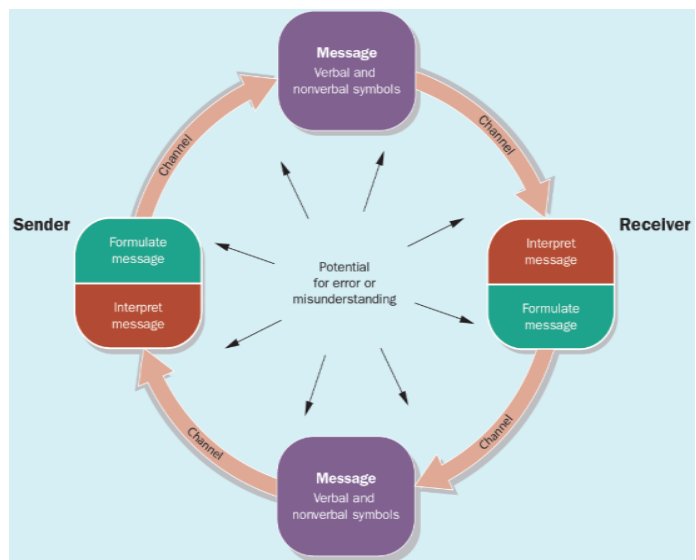

Gambar 1. Model Komunikasi Interpersonal (Daft, 2015) 
Metoda komunikasi dibedakan atas komunikasi verbal dan non verbal. Yang termasuk dalam verbal adalah lisan dan tulisan, sedangkan non verbal adalah isyarat, bahasa tubuh, juga intonasi. Berdasarkan hasil penelitian, non verbal ternyata memiliki dampak yang jauh lebih besar daripada verbal. Seringkali komunikasi tidak berjalan sebagaimana mestinya karena adanya hambatan. Hambatan komunikasi yang sering terjadi adalah filtering, persepsi selektif, informasi berlebihan, emosi, bahasa, adanya rasa takut, dan juga perbedaan gender. Filtering terjadi bila pengirim pesan memanipulasi informasi sehingga informsi tersebut dipandang lebih menyenangkan bagi si penerima pesan.

Dalam berkomunikasi penting sekali menerapkan adanya komunikasi emphatik. Komunikasi emphatik adalah kemampuan untuk menangkap, memahami, dan merasakan makna dari sudut pandang orang lain. Dimana dalam hal ini kita harus lebih dahulu berusaha untuk memahami orang lain, baru kemudian minta untuk dipahami. Komunikasi emphatik dapat tercapai melalui banyak mendengarkan. Dalam komunikasi emphatik, yang penting tidak hanya isi pesan (content), tetapi juga bagaimana pesan tersebut disampaikan (context). (Robbins and Judge, 2017)

\section{Dokumentasi Pelatihan dan Pengembangan: Kepemimpinan dan Komunikasi}

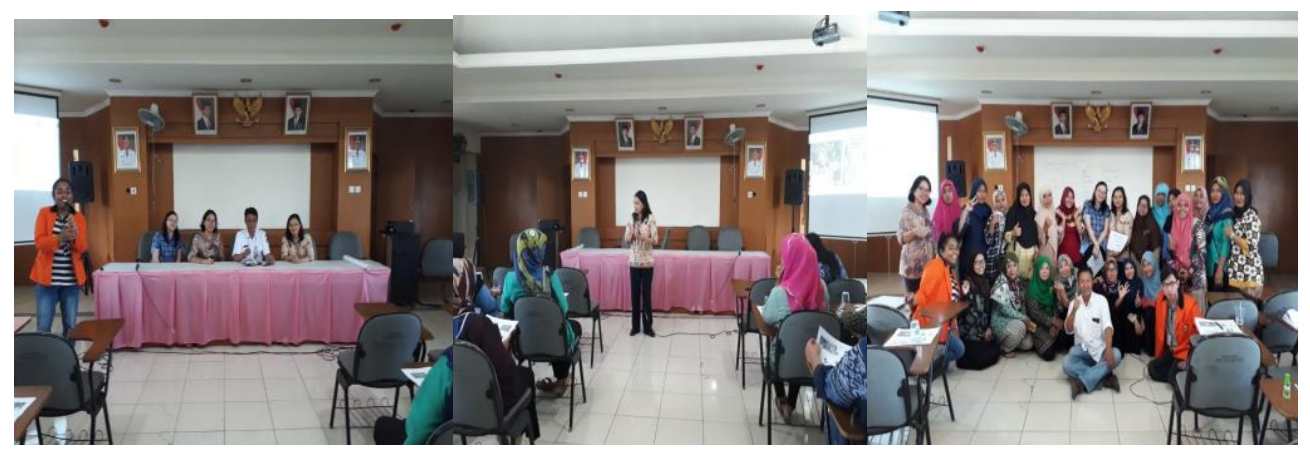

Gambar 2. Foto Kegiatan

Selama berlangsungnya kegiatan, mendapatkan respon yang positif. Khalayak sasaran aktif terlibat dalam diskusi dan tanya jawab. Juga setelah kegiatan proses pendampingan dan edukasi menjadi lebih efektif dan komunikasi berjalan lebih baik, seperti terlihat pada Gambar 2. Hasil evaluasi terhadap kegiatan ini juga sangat baik dan pihak GNI berharap proses kerjasama ini tetap dapat terus berkelanjutan. Topik Kepemimpinan dan Komunikasi dirasa sangat sesuai dengan kebutuhan di lapangan. Dalam pelaksanaannya terdapat beberapa kendala, yaitu: kegiatan yang dilakukan di pagi hari berbarengan dengan jadwal kerja atau jadwal berdagang, sehingga beberapa ada yang tidak hadir dan ada juga yang terlambat datang dan rendahnya pemahaman akan pentingnya pengembangan masyarakat.

\section{KESIMPULAN DAN SARAN}

Kegiatan pengabdian masyarakat ini dilaksanakan selama empat bulan. Tahap awal dimulai dengan melakukan training needs analysis (TNA). Aktivitas pengembangan dimulai dengan persiapan proyek, menyusun jadwal pelaksanaan, asessment, dan pelatihan dan pengembangan dengan topik Kepemimpinan dan Komunikasi. Metode yang dipilih adalah pelatihan dan pengembangan, serta pembimbingan dan pendampingan dengan berbagi ilmu dan pengalaman kepada khalayak sasaran dan mitra. 
Ke depannya pengembangan masyarakat Cakung akan terus dilakukan. Evaluasi kegiatan akan dilaksanakan tidak hanya laporan kegiatan, namun juga dilakukan laporan naratif, monitoring dan evaluasi terhadap pelatihan dan pengembangan, juga pendampingan (Pemantauan dan evaluasi lapangan akan dilaksanakan untuk mengumpulkan data, dokumen, informasi (kualitatif \& kuantitatif) terkait dengan pengelolaan resiko atas kegiatan), dan cross-learning.

\section{Ucapan Terima Kasih}

Terimakasih kepada Yayasan Gugah Nurani Indonesia, mitra FEB-Universitas Katolik Indonesia dalam membangun bangsa Indonesia.

\section{REFERENSI}

Achua, Christopher F., and Lussier, Robert N (2013). Effective Leadership, 5th ed, Cengage Learning.

Daft, Richard L (2015). The Leadership Experience, 6th ed., Cengage Learning.

Dessler,Gary (2017). Human Resource Management, 15th ed, Pearson Education

Gugah Nurani Indonesia, (2017), Project Proposal: Training for Batavia CDP Community Development Committee by FE Universitas Atma Jaya, GNI-Jakarta

Lacerenza, Christina N., Reyes, Denise L., Marlow, Shannon L., Joseph, Dana L., and Salas, Eduardo. (2017). Leadership Training Design, Delivery, and Implementation: A MetaAnalysis. Journal of Applied Psychology, 102 (12), 1686-1718.

Moorhead, Gregory., and Griffin, Ricky W (2012). Managing Organizational Behavior, $10^{\text {th }}$ ed., Cengage Learning.

Noe, Raymond A (2010). Employee Training and Development, 5th ed, McGraw- Hill International Ed.

Pieper, Angelique Bakker., and de Vries, Reinout E. (2013). The Incremental Validity of Communication Styles Over Personality Traits for Leader Outcomes. Journal of Human Performance, 26, 1-19.

Robbins, Stephen.P., \& Judge, Timothy A (2017). Organizational Behavior, $17^{\text {th }}$ ed, Pearson International Edition.

Snell, Scott., and Bohlander, George. (2013). Principles of Human Resource Management. 16th edition. Cengage Learning-South Western. 